\title{
Energy Consumption Performance Analysis of Electrical Mitad at Mekelle City
}

\section{Mesele Hayelom Hailu*, Mulu Bayray Kahsay, Asfafaw Haileselasie Tesfay and Oumer Issa Dawud}

School of Mechanical \& Industrial Engineering, EiT-M, Mekelle University, Mekelle, Ethiopia (*meseleha@yahoo.com).

\begin{abstract}
The Injera baking electrical mitad is the most energy-consuming device in every household in Ethiopia. This research presents a detail engineering study on the energy-consumption performance of existing electrical mitad in Mekelle city. The research work considered thirty-one electrical mitad from different workshops in Mekelle. Depending on the number of clay used, there are three types of electrical mitad; the single clay, the double clay and the rotating type mitad. In this research, it was found out that the average power consumption of existing mitad is in the range of $3.5 \mathrm{KW}$ to $3.9 \mathrm{KW}$. The specific average baking energy is $0.82,0.73$ and $0.54 \mathrm{kWh} / \mathrm{kg}$ of injera for double clay, single clay and rotating type mitad respectively while the thermal efficiency by considering baking of $6 \mathrm{~kg}$ of Injera on each mitad is $38 \%, 47 \%$ and $61 \%$ respectively. In all designs, the baking temperature is in the range of $130-140{ }^{\circ} \mathrm{C}$. Although the rotating type mitad is more energy efficient, it has technical limitations. Due to that, the single and the double clay mitad are widely used by households hence share all the market penetration of injera baking electrical mitad. These commonly used electrical mitad have an energy loss from $50-60 \%$ of the input energy.
\end{abstract}

Keywords: Electrical mitad, Injera baking energy, Thermal efficiency, Baking temperature, Ethioopia.

\section{INTRODUCTION}

The household sector in Ethiopia accounts for about $89 \%$ of the total energy consumption and this sector also consumes about $96 \%, 15 \%$ and $33 \%$ of the total energy from biomass, petroleum and electricity respectively (GiZ, 2011). Studies show that domestic energy requirements are primarily for baking and cooking purposes; accounting for about $60 \%$ of households' energy consumption (Gebreegziabher, 2004, 2007; RPTC, 1998), making the electric mitad as the most energyconsuming device in every household in Ethiopia.

Though the use of electricity for Injera baking is limited to urban dwellers, the Injera baking electrical mitad contributes to large energy consumption in the electricity supply system of the country (Dave, 2010). It is widely perceived that the efficiency for energy consumption of the existing electrical mitad is low arising from old design and its manufacturing defaults. The current mitad design dates back to 1960's when baking of Injera electrical mitad started with high-income groups in cities. However, since then, almost no design improvements have taken place (Dave, 2010). Furthermore, since electrical mitad is manufactured traditionally with untrained workers, it Momona Ethiopian Journal of Science (MEJS), V9(1):43-65, 2017 (C)NCS, Mekelle University, ISSN:2220-184X 
is expected that it will have lower energy consumption efficiency hence a wider room for improvement.

There are some studies on the existing electrical mitad (Dave, 2010; GIZ, 2011; Alula Gebresas and Asmamaw Tegegne, 2011; Awet, 2011; Gebreegziabher, 2004, 2007; RPTC, 1998) and on improved mitad design (Dave, 2010). A World Bank study report on existing injera baking mitad (Dave, 2010) discusses the different existing technologies (wood stove, electrical mitad) and some new emerging technologies (solar stove, the rotating type mitad, electro-induction mitad and automated electrical mitad in the USA). It also indicated a qualitative assessment of the energy consumption losses and improvement options of the existing designs (Alula Gebresas and Asmamaw Tegegne, 2011; Awet, 2011) have also studied the thermal conductivity of the clay material and its improvement. However, the existing studies lack detail engineering analysis on the energy consumption performance of the whole system as well as it components and indication of the different opportunities for improvement of energy consumption.

Even though it is inefficient, the apparatus has high market penetration and it is continuing at its current higher energy consumption and lower efficiency, subsequently higher monthly energy bill for the consumers and high energy 'waste' for the national grid. The utilization of efficient and improved appliances is one of the opportunities for the reduction of energy consumption and efficient utilization of the limited energy resource of the country. This will help to reduce the burden on the power plant as well as national grid, decreases monthly billing amount; these all subsequently contribute for the economic development of the country.

This paper is therefore, designed to fill the above gap and contribute for upcoming studies that intervene in the direction of developing improved injera baking electrical mitad. In line to this objective, this research has conducted a detail engineering study of the energy-consumption performance of existing electrical mitad in Mekelle city and indicated options of improvement.

\section{METHODOLOGY}

The research assessed the existing electrical mitad in Mekelle city and investigated the different parts, dimensioning and analyzing of the thermal property of the different components of the mitad. Sample prototype electrical mitad are purchased for extensive experimentation on energy consumption characteristics. Additional direct experimentation is also conducted at different mitad workshops and existing mitad at Mekelle University student cafeteria. The energy consumption 
measurement are then extensively analyzed to determine the energy efficiency, losses of the different mitad and hence to indicate the energy consumption improvement options.

\section{DESCRIPTION OF THE EXISTING ELECTRICAL MITAD}

Depending on the number of clay used, there are three type of electric mitad in Mekelle city: the single clay, the double clay and the rotating type mitad, as described in figure 1. The single clay mitad comprises only one baking clay with the top surface used as baking surface and the electrical resistor is embedded at the bottom side of the clay. In the double clay mitad, there are two layers of clay placed one on top of the other. The upper clay (also called the dependent clay) is used as the baking clay and the second clay (also called the heating clay) is used to embed the electrical resistor. The rotating type mitad is comprised of two layers of clay. Both clays are placed back-toback and the front side of both clays is used as baking surface. The electrical resistor is embedded in the bottom side of either of the two clay. The clay embedded with the electrical resistor is the called the heating clay while the other clay is called the dependent clay. The baking process is conducted by rotating the mitad one after the other.

The widely available injera baking electrical mitad in Mekelle city are the single clay and double clay type. The clay for double layer mitad is commonly in the range of 12 to $22 \mathrm{~mm}$ thick; about 12 to $14 \mathrm{~mm}$ thick for top (baking) clay and 16 to $22 \mathrm{~mm}$ thick for bottom (heating element holder) clay. The clay diameter is similar for both type, in the range of 550 to $580 \mathrm{~mm}$. Other information of the mitad is summarized in table 1 .

Table 1. Physical dimension of the different components of the existing mitad.

\begin{tabular}{|l|l|}
\hline Parameters & Dimensions \\
\hline Number of grooves & $10-11$ patterns \\
\hline Groove depth & $7-8.5 \mathrm{~mm}$ \\
\hline Groove diameter & $8 \mathrm{~mm}$ \\
\hline Pitch distance & $17.5 \mathrm{~mm}$ \\
\hline Resistor coil diameter & $6 \mathrm{~mm}$ \\
\hline Resistor wire diameter & $0.9 \mathrm{~mm}$ \\
\hline Resistor coil length-before stretching & $650 \mathrm{~mm}$ \\
\hline Resistor coil length-after stretching & $9600 \mathrm{~mm}$ \\
\hline Circuit connection type & parallel \\
\hline Average clay thickness & $20 \mathrm{~mm}$ \\
\hline Average clay diameter & 550 to $580 \mathrm{~mm}$ \\
\hline Bottom insulation thickness & 30 to $35 \mathrm{~mm}$ \\
\hline
\end{tabular}




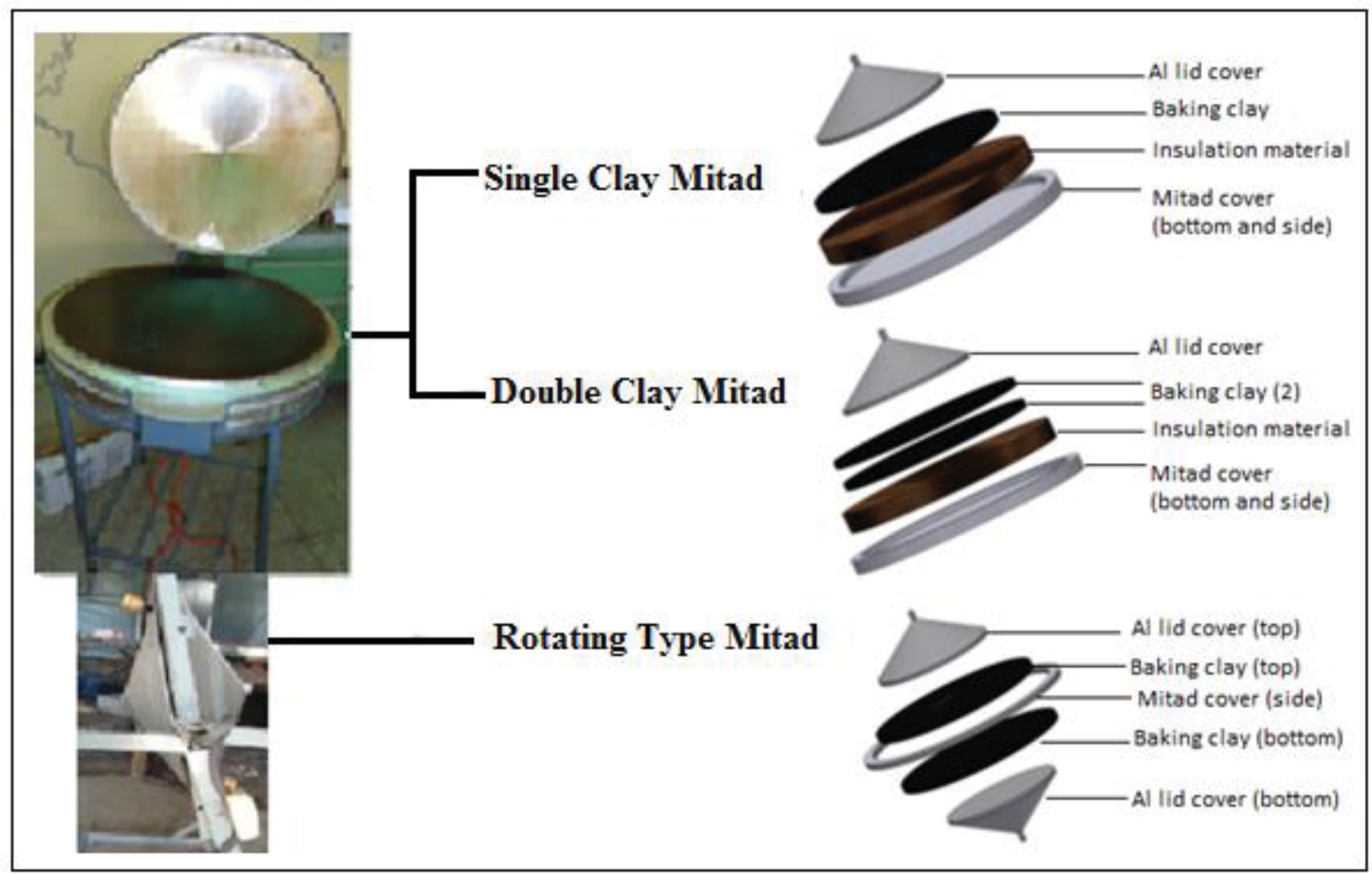

Figure 1. Description of the three type of Electric Mitad at Mekelle City.

\subsection{Experimental Setup}

The experimental setup on each mitad is established to take temperature measurements at the different points of the mitad. The experimental set-up is similar for all types with minor difference on the rotating type; as discussed in the following section.

\subsection{Common Setup for all Mitad}

The measurement points for all mitad are indicated in figure 2. Temperature measurement has been taken at the following points, for all mitad:

- At the center of the hot clay bottom (the face at which heating elements embedded)

- At $14 \mathrm{~cm}$ from the center of hot clay at bottom

- At $27 \mathrm{~cm}$ from the center of hot clay at bottom (near to the border edge of the clay)

- Conical Aluminum lid cover, at the center tip

- Intermittent measurements for hot clay between the periods when the baker women is preparing the clay for baking until she started placing of batter

- Temperature of Injera right after removed from the mitad

- $\quad$ Room atmospheric temperature and batter temperature 


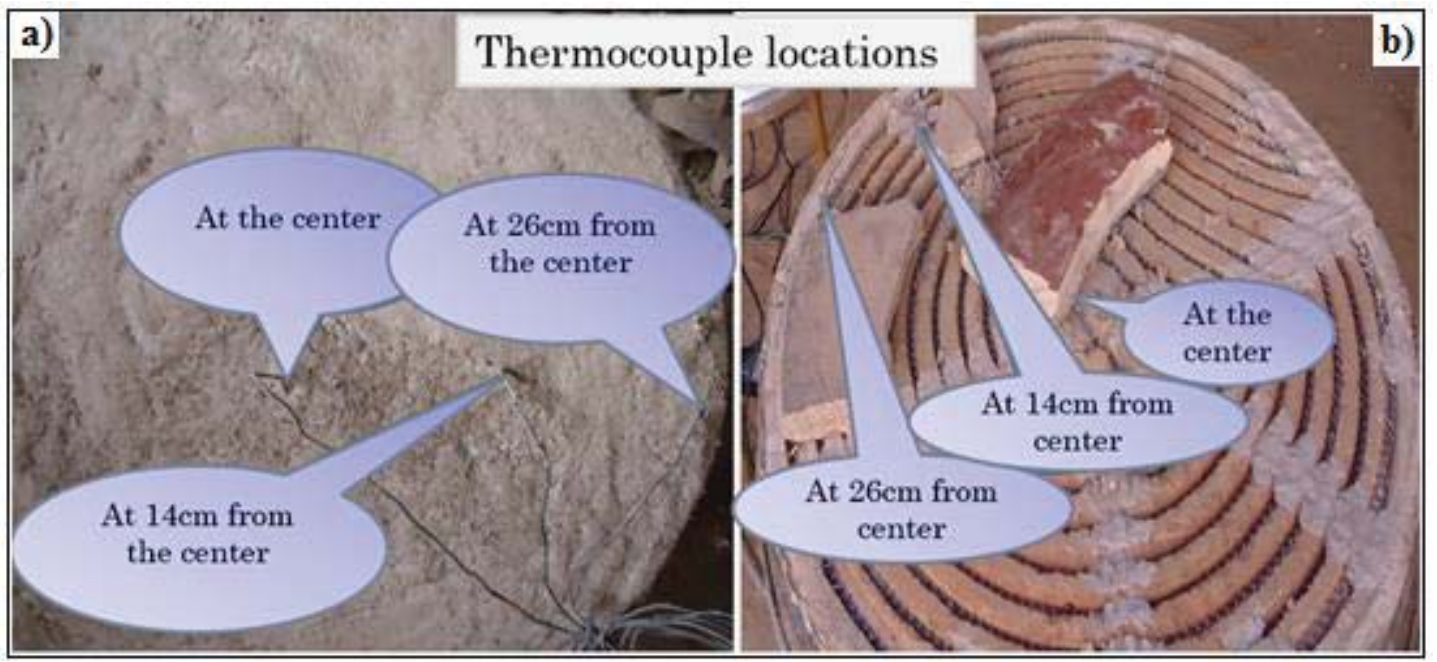

Figure 2. Position of thermocouples at the bottom of hot clay, (a) single clay type, (b) double clay type.

\subsection{Additional Test Setup for Single and Double Clay types}

In addition to the above measurement points, temperature measurement for the single clay and the double clay mitad has been taken at the body top, body bottom and insulation bottom center. The measurement point at the different sections of the single later and double layer type mitad is as indicated in figure 3.

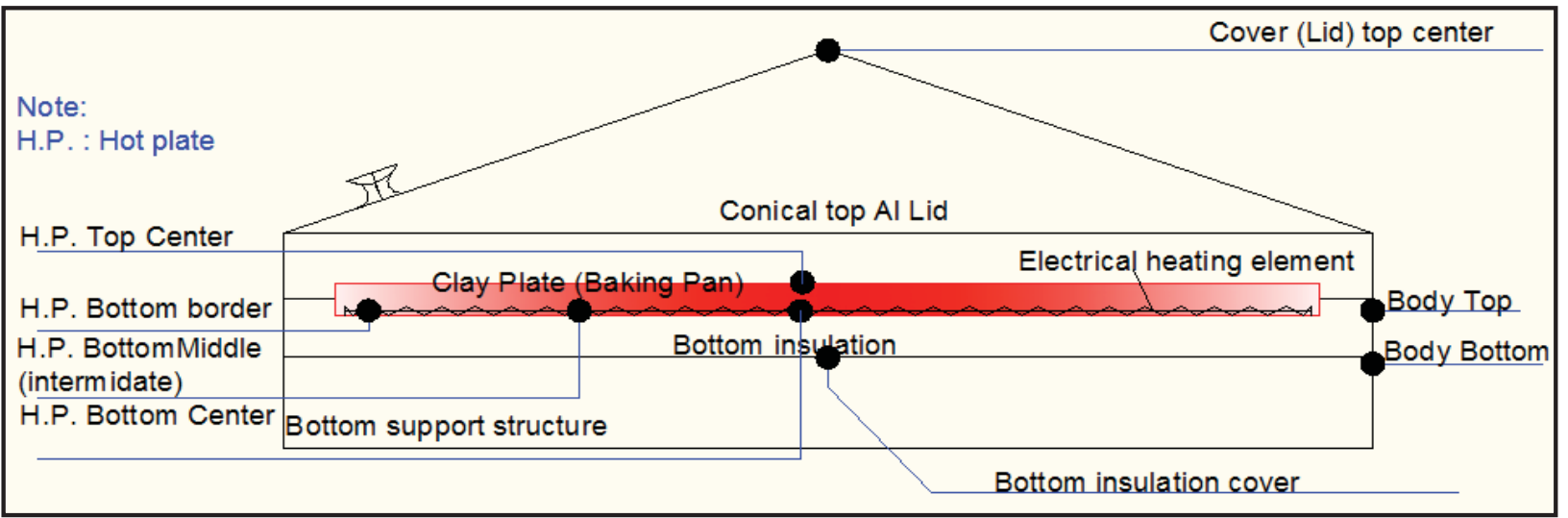

Figure 3. Configuration of measurement points for single and double clay type mitad.

\subsection{Additional Test Setup for Rotating type Mitad}

Similarly the measurement points at the different section of the rotating type mitad are:

- At the center of the external body (i.e. at the junction point of the two mitad Al cover)

- At both of the conical aluminum lid covers

- At both of the top body corners near to the clay edge 
The measurement point at the different sections of the rotating type mitad is as indicated in figure 4.

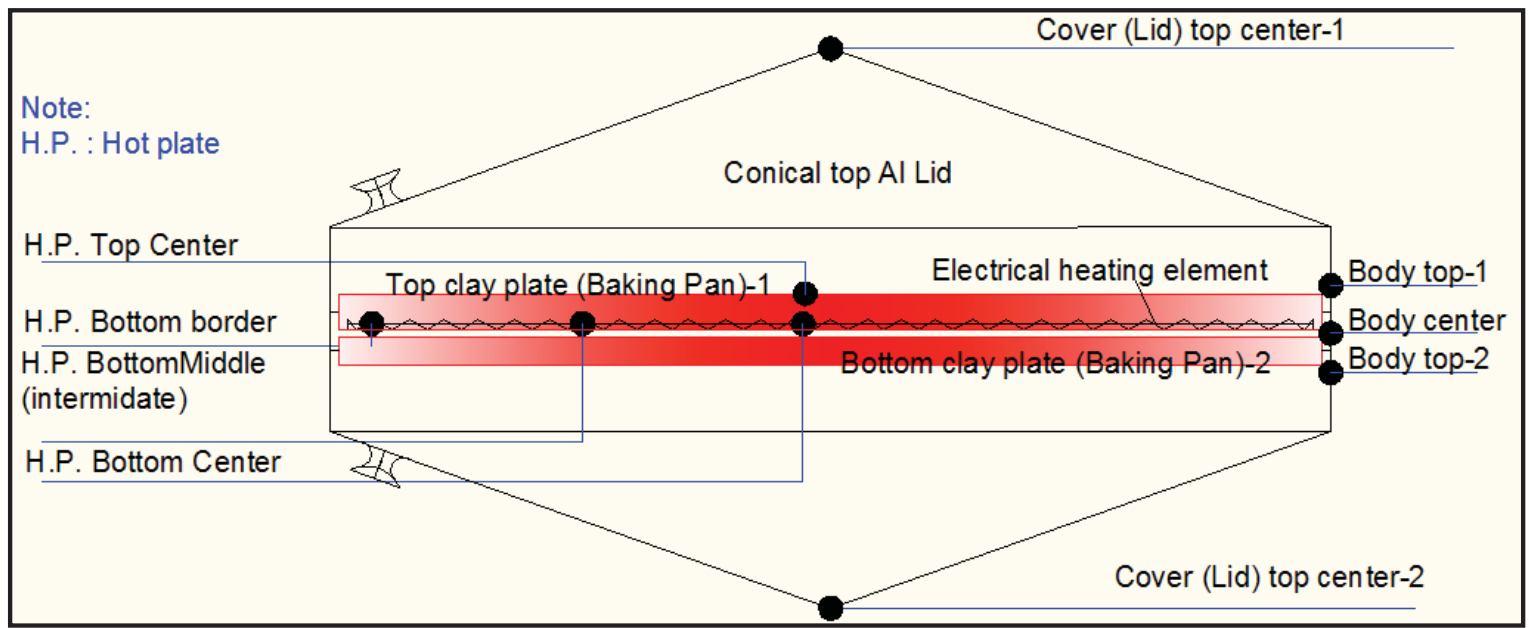

Figure 4. Configuration of measurement points for rotating type mitad.

\subsection{Material and Equipment used in the Experiment}

The other experimental setup also includes computer for recording of thermocouple data, balance to measure the weight of the injera and the data logger to connect the thermocouple with the simulation software; clamp meters for the measurement of AC-current and AC-voltag; multi-meter for the measurement of line $\mathrm{AC}$ voltage and temperatures and energy meter for measurement of the energy consumption of the Injera baking mitad were also used. This additional experimental setup is indicated in figure 5 .

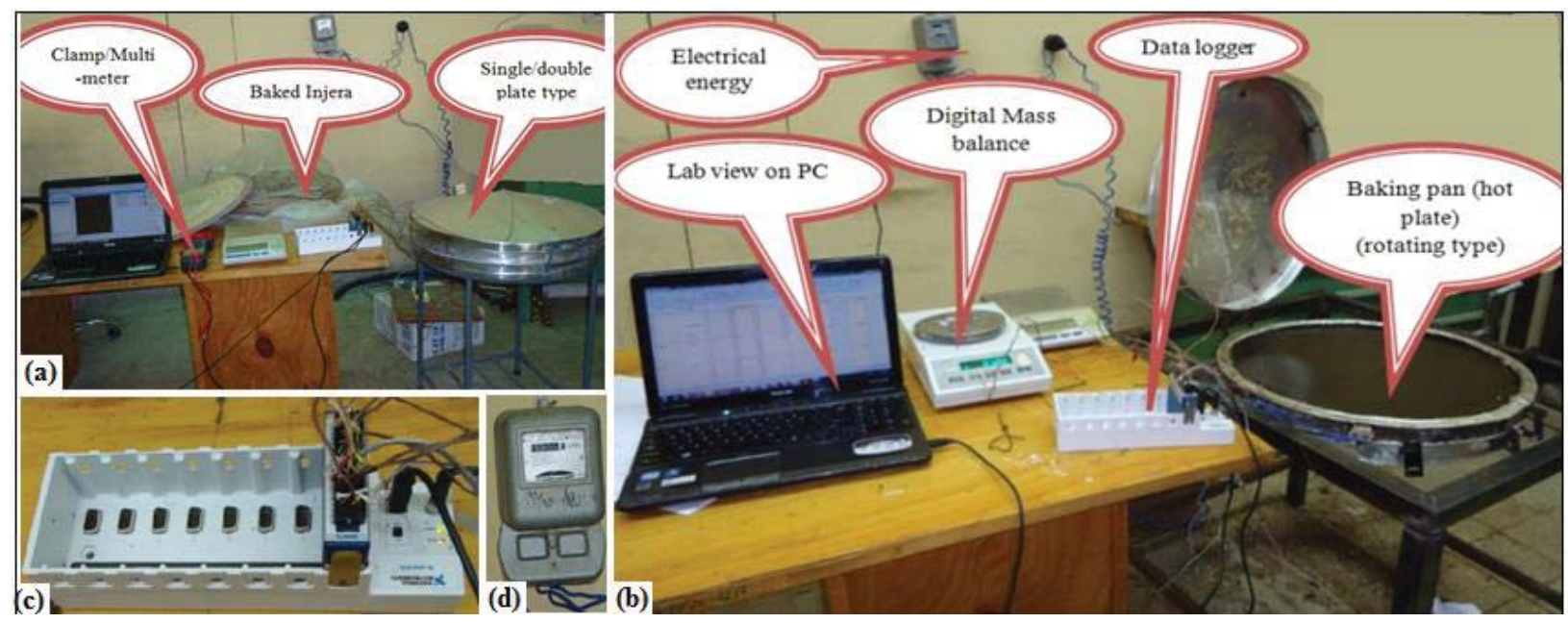

Figure 5. Additional experimental setup and equipment, (a) set up for single/Double clay type mitad, (b) set up for rotating type mitad, (c) data logger and (d) electrical meter. 


\subsection{Modeling the Baking Process Heat Transfer Mechanism of Mitad}

The energy transfer from heating element to the baking clay, side and bottom insulations is through conduction heat transfer. On the other hand the stove experienced a considerable natural convection and radiation heat losses from its surfaces to the surrounding room.
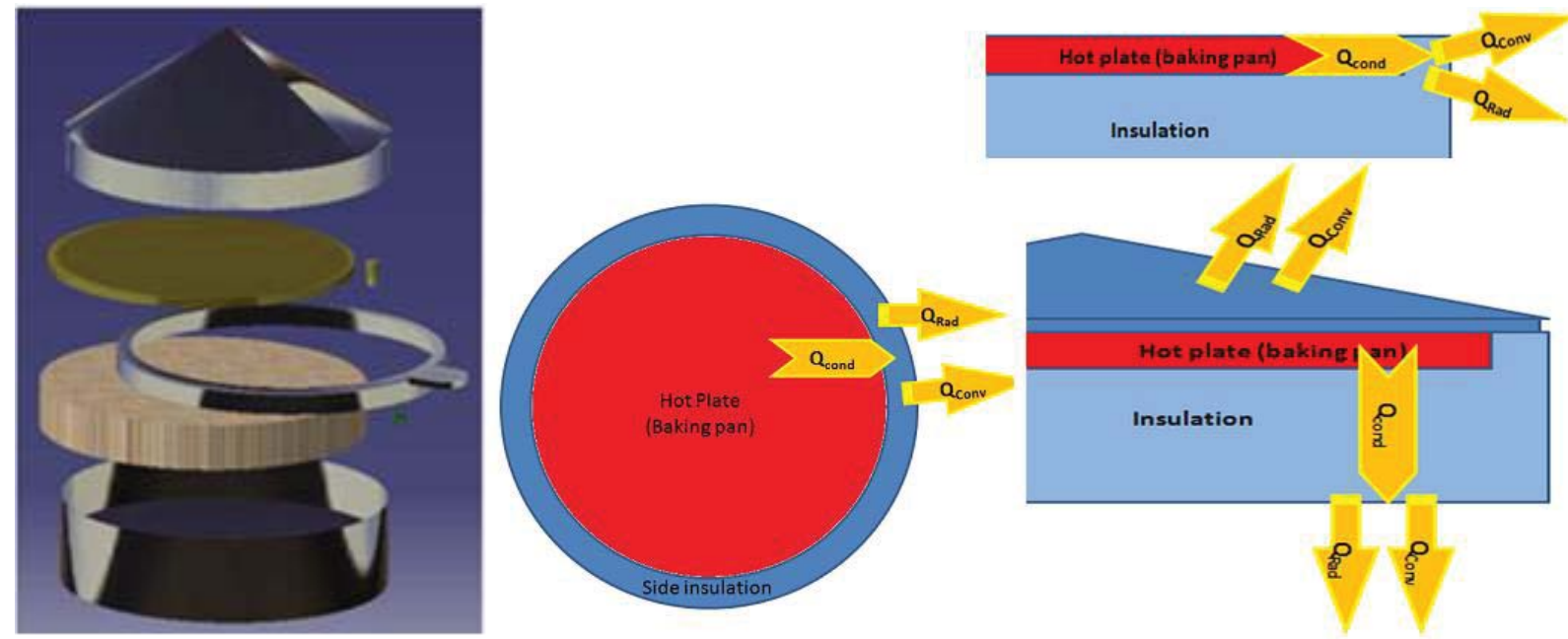

Figure 6. The heat transfer mechanisms of an Injera baking electrical mitad.

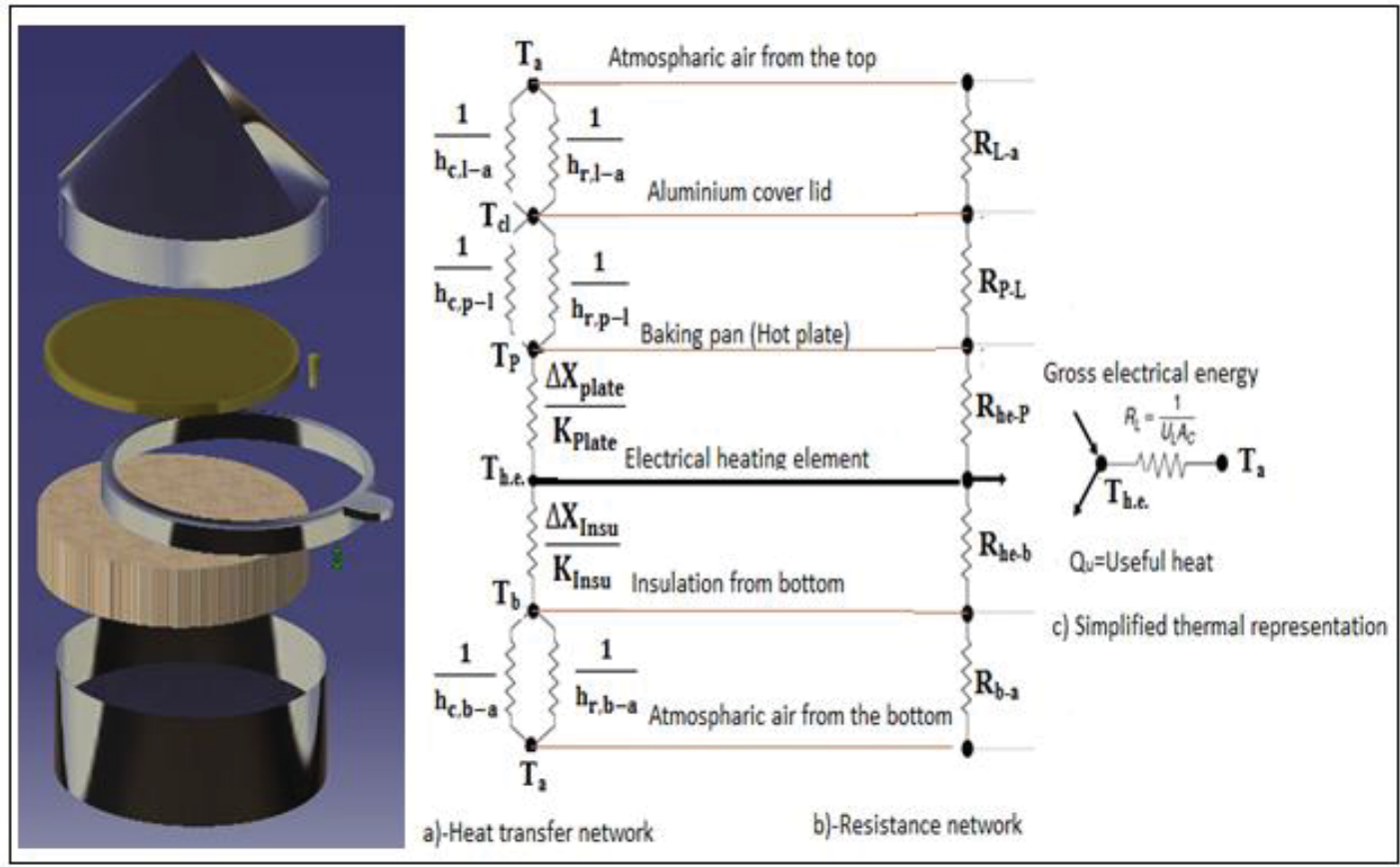

Figure 7. Thermal and electrical resistance model of an Injera baking mitad.

The heat transfer mechanisms of the electric mitad has shown in figure 6. The heat energy produced by the electrical resistor is then transferred to the top part is consumed in the baking 
process and the remaining heat is transferred loses to the atmosphere. The heat loss of the system has tried to reduce by using an insulation in tis side and bottom part. The governing equation for the three types of heat transfer mechanism have represented by basic heat transfer equations.

From basic heat transfer principle, the thermal and electrical resistance network of the mitad by considering the mitad construction components from left to right (horizontal plane sectioning) is represented in figure 7.

\subsection{The Useful Energy of the Baking Process}

The average energy required for Injera baking implies the energy that is necessary to raise the temperature of batter from room temperature to boiling point and evaporate the required amount of water during the baking process. This useful baking energy if estimated in the form of sensible heat for heating-up of the batter from room temperature to water boiling temperature and Latent heat responsible for evaporating some of the water content of the batter. The net useful energy in Injera baking has modeled mathematically in equation1.

$$
\mathrm{E}_{\text {useful }}=\mathrm{m}_{\text {batter }} \mathrm{C}_{\text {P.batter }}\left(\mathrm{T}_{\text {boil }}-\mathrm{T}_{\text {room }}\right)+\left(\mathrm{m}_{\text {batter }}-\mathrm{m}_{\text {injera }}\right) \mathrm{h}_{\text {vaporization }}
$$

\subsection{Heat Losses of the Baking Process}

The heat transfer mechanism of the mitad is modeled in Figure 8. Considering an overall energy balance on the Mitad system, the heat losses has calculated using eq.2:

$$
\mathrm{Q}_{\text {losses }}=\mathrm{Q}_{\text {rad,top }}+\mathrm{Q}_{\text {conv,top }}+\mathrm{Q}_{\text {rad,bottom }}+\mathrm{Q}_{\text {conv,bottom }+} \mathrm{Q}_{\text {rad,side }}+\mathrm{Q}_{\text {conv,side }}
$$

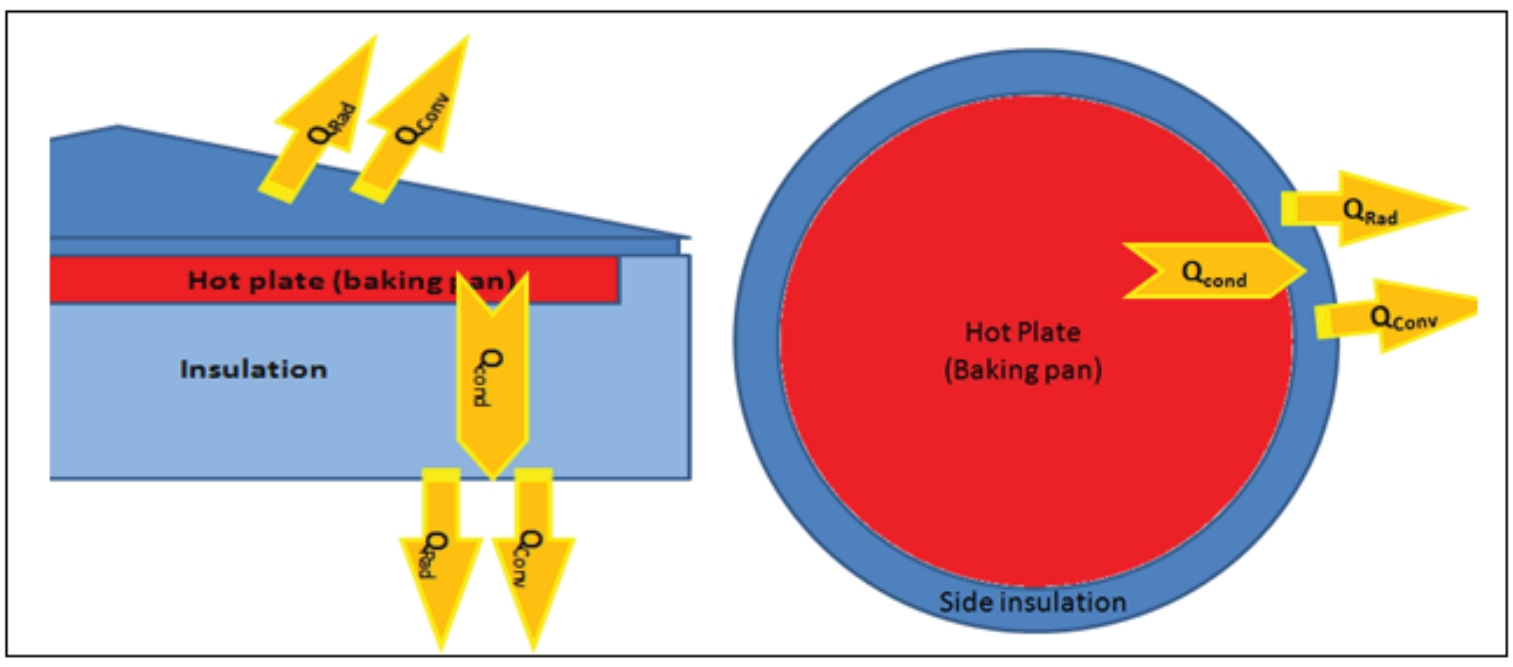

Figure 8. Heat loss mechanism of an Injera baking Mitad. 
The governing equation for the Convection heat transfer and the radiation heat transfer mechanism can be represented by basic heat transfer equations (Adrian, et al., 2003; Frank, et al., 2011; John, et al., 2008; Incropera, et al., 2007; Yunus, 2002) as:

$$
\mathrm{Q}_{\mathrm{cov}}=\mathrm{Ah}\left(\mathrm{T}_{\mathrm{f}}-\mathrm{T}_{\mathrm{s}}\right)=\mathrm{Ah} \Delta \mathrm{T} \quad \text { and } \quad \mathrm{Q}_{\mathrm{rad}}=\varepsilon \sigma \mathrm{A}\left(\mathrm{T}_{\mathrm{s}}^{4}-\mathrm{T}_{\infty}^{4}\right)
$$

\subsection{Input Energy of the Baking Process}

The heat generated by the heating system, Qheat is the input energy for the baking process. This input energy is a function of voltage (V) and the current (I) flowing across the heating element, this relation is given in eq.4.

$$
\mathrm{Qheat}_{\mathrm{H}}=\mathrm{VI}
$$

\subsection{Thermal Efficiency of the System}

The system thermal efficiency is the ratio of net useful energy utilized to the gross energy supply, which is computed by using equation 6 .

$$
\text { Thermal efficiency }=\frac{\text { Usefull energy utilized }}{\text { Gross input energy required }}>>\quad \eta_{\text {thermal }}=\frac{E_{\text {Usefiul }}}{E_{\text {input }}}
$$

\section{RESULTS AND DISCUSSION}

In this research, the energy consumption characteristics of the existing electrical mitad in Mekelle city is determined and described by determining its baking power, baking temperature, baking process temperature profile, useful energy consumption, energy loss and thermal energy efficiency. These results are discussed below.

\subsection{Baking Power of the Existing Mitad}

The measurements taken to investigate the baking power of the existing mitad by considering thirty-one electrical mitad from different workshops in Mekelle and Mekelle University main campus student cafeteria as presented in table 2 . The line voltage was in the range of $207 \mathrm{~V}$ to 214 volts, therefore, for an average line voltage of $210 \mathrm{~V}$, the average power requirement, the Baking Power, of existing electrical mitad in Mekelle city is in the range of $3.53 \mathrm{~kW}$ to $3.95 \mathrm{~kW}$. Therefore, as per the existing rating of the conventional equipment, the electrical mitad is the most energyconsuming device in every household.

\subsection{Baking Temperature}

An investigation of the baking temperature of the electrical mitad is an important indicator about the energy consumption behavior of the equipment. This temperature reading is taken from the top 
Table 2. Power rating of the existing electrical mitad.

\begin{tabular}{|c|c|c|c|c|}
\hline Item description & Unit & Qty & Current (A) & Remark \\
\hline MU-Electric mitad-1 & Pcs & 1 & 20.30 & \multirow{10}{*}{$\begin{array}{l}\text { On average, the electrical mitad at Mekelle } \\
\text { university are consuming about } 18.83 \\
\text { Amperes of current }\end{array}$} \\
\hline MU-Electric mitad-2 & Pcs & 1 & 18.60 & \\
\hline MU-Electric mitad-3 & Pcs & 1 & 20.00 & \\
\hline MU-Electric mitad-4 & Pcs & 1 & 15.60 & \\
\hline MU-Electric mitad-5 & Pcs & 1 & 18.50 & \\
\hline MU-Electric mitad-6 & Pcs & 1 & 19.20 & \\
\hline MU-Electric mitad-7 & Pcs & 1 & 18.30 & \\
\hline MU-Electric mitad-8 & Pcs & 1 & 21.00 & \\
\hline MU-Electric mitad-9 & Pcs & 1 & 18.00 & \\
\hline \multicolumn{4}{|c|}{ Random samples at producers workshop } & \\
\hline Random samples-A & Pcs & 16 & 17.50 & They are all in the range of 17.2 to 18.1 \\
\hline Random samples-A & Pcs & 2 & 16.80 & \\
\hline Random samples-A & Pcs & 1 & 12.00 & Waiting for renovating to be changed to $16 \mathrm{~A}$ \\
\hline \multicolumn{4}{|c|}{ Purchased for this experimental work } & \\
\hline Single-1 & Pcs & 1 & 17.00 & \multirow{3}{*}{$\begin{array}{l}\text { On average they are consuming about } 17.3 \\
\text { Amperes of current }\end{array}$} \\
\hline Double & Pcs & 1 & 17.40 & \\
\hline Rotating type & Pcs & 1 & 17.50 & \\
\hline
\end{tabular}

\section{Single plate type Mitad-duirng baking plots}

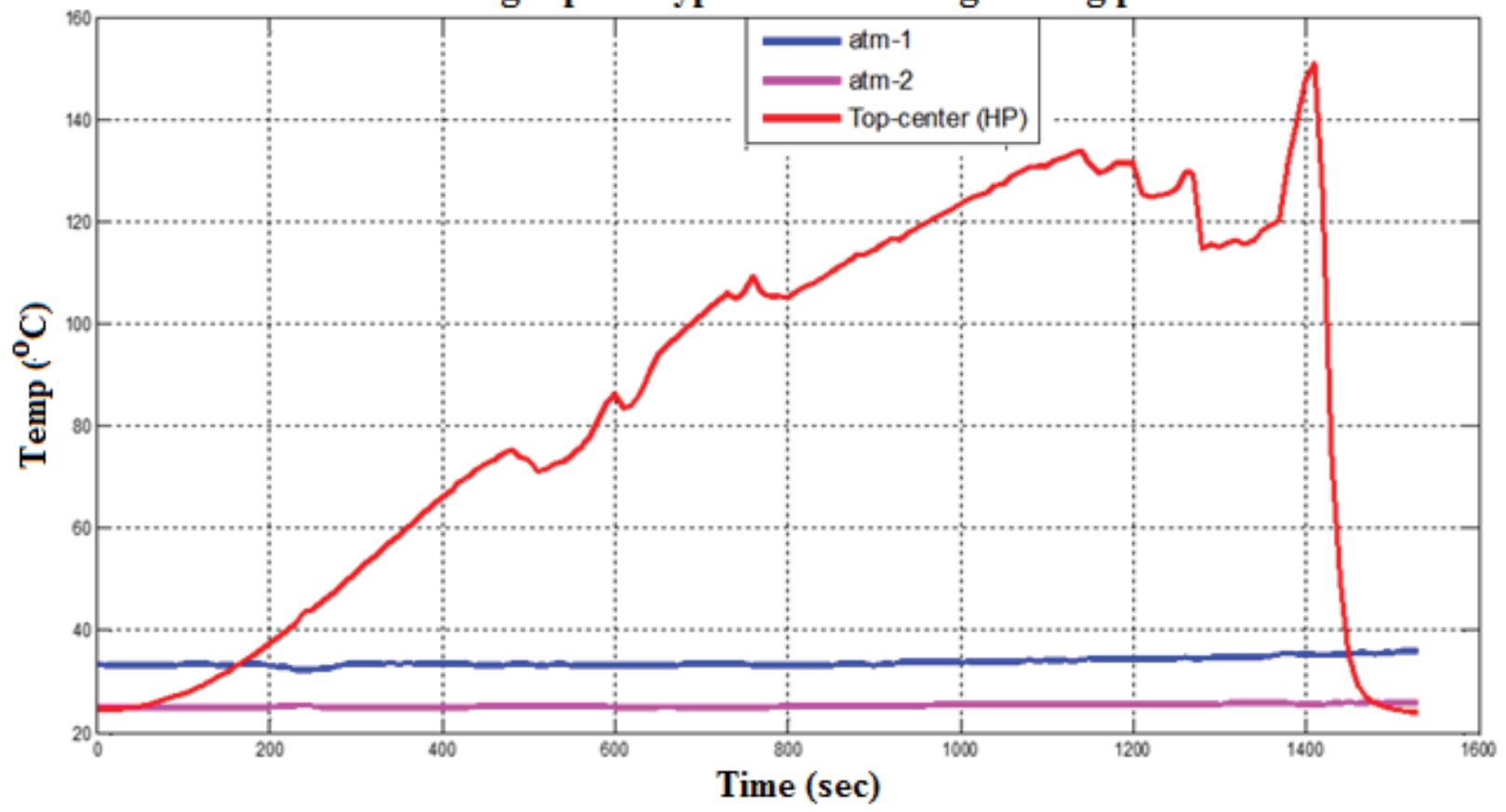

Figure 9. Baking temperate of the single clay type electrical mitad. 


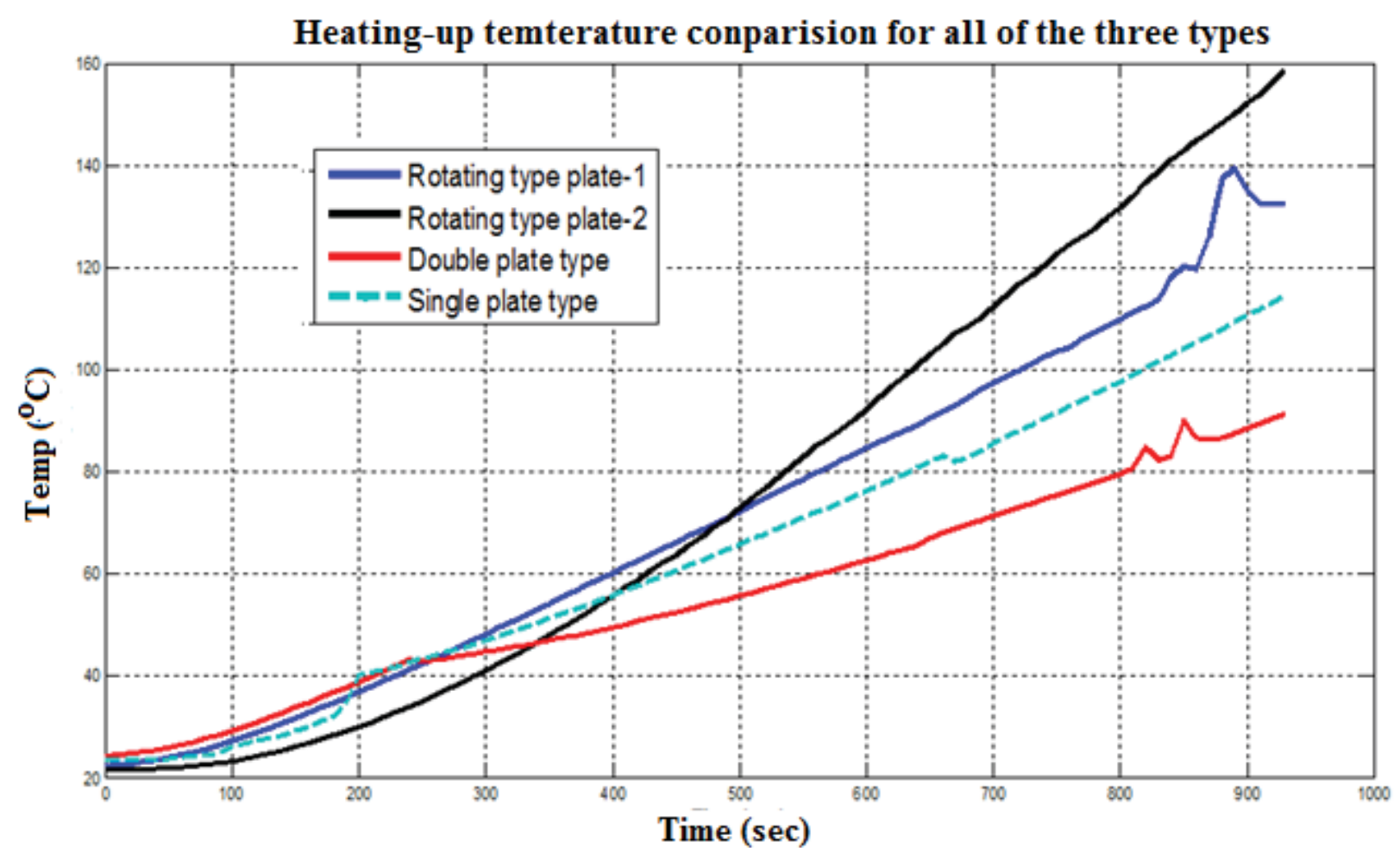

Figure 10. Heating-up temperature comparisons for top surface of the three type of mitad.

surface of the baking pan. The temperature profile for the baking process in the single clay type mitad is indicated in figure 9. It can be observed that the baking temperate is in the range of 130 $140^{\circ} \mathrm{C}$. The remaining curves in figure 9 shows the room temperature (near mitad) and the batter temperature. Similar temperate range has been observed in other type of mitad i.e. the double clay and rotating type mitad.

\subsection{Baking Process Temperature Profile}

The baking process temperature profile is another important indicator about the energy consumption behavior of the equipment. The temperature profile of the mitad is determined into two conditions: with no load and with load conditions.

\subsection{No Load Temperature Measurements}

This was done to determine the energy requirements for heating-up, heating rate and time. The heating up temperature development of the three type of mitad is indicated in figure 10.

It can be clearly understood that the rotating type electrical mitad has a faster heating-up period than the others. This faster heating rate is attained as the heat source in this type of mitad is sandwiched between the two baking clays as a result it would likely has minimal losses hence 
contributing to faster heating up of both clays. The thickness of the clays, which are $14 \mathrm{~mm}$ for the main clay (heating element holder) and $10 \mathrm{~mm}$ for dependent clay have also contributed to relatively faster heat up of the clay surfaces. The single clay type mitad has better heating-up speed than the double clay mitad.

The average energy consumption for the baking process to start is summarized in table 3 . It has been observed that the double layer mitad has the slowest response time and the highest energy consumption while the rotating type has attained the required temperature with in short period of time and relatively smaller energy consumption. Therefore, analogous to the temperature development, the rotating type mitad consumed the least energy (for two baking clay) as compared to the other type of mitad.

Table 3. Comparison of energy consumption for heating up process.

\begin{tabular}{|llll|}
\hline \multirow{2}{*}{ Description } & \multicolumn{3}{c|}{ Mitad Type } \\
\cline { 2 - 4 } & Rotating type & Single clay & Double clay \\
\hline Input Voltage $(\mathrm{V})$ & 207.00 & 207 & 207 \\
\hline Input Current $(\mathrm{A})$ & 17.50 & 17 & 17.4 \\
\hline Mitad power requirement $(\mathrm{kW})$ & 3.62 & 3.52 & 3.60 \\
\hline Consumed energy to attain $130^{\circ} \mathrm{C}(\mathrm{kWh})$ & 1.15 & 1.10 & 1.32 \\
\hline Required time for heating-up $(\mathrm{min})$ & 15 & 20 & 24 \\
\hline
\end{tabular}

\subsection{With Load Temperature Measurements}

The temperature profile measurement is done while conducting the baking process on each type of mitad. Figure 11a indicates the temperature profile of the different sections of the single clay mitad. The top three curves represent the temperature measurements of the hot clay bottom surface. Those three points record temperatures starting from ambient temperature to the maximum of upto $580^{\circ} \mathrm{C}$. The top side clay has reached the required baking temperature of $130^{\circ} \mathrm{C}$ with the time requirement of 20 minutes. It can also be noted that the clay is heated non-uniformly (i.e. $580^{\circ} \mathrm{C}$ at $14 \mathrm{~cm}$ from center, $395^{\circ} \mathrm{C}$ at $26 \mathrm{~cm}$ from the center and $350^{\circ} \mathrm{C}$ at center). The remaining curves in figure 11a shows the temperature profile of the different components of the mitad such as the top cover, bottom insulation and room temperature. 


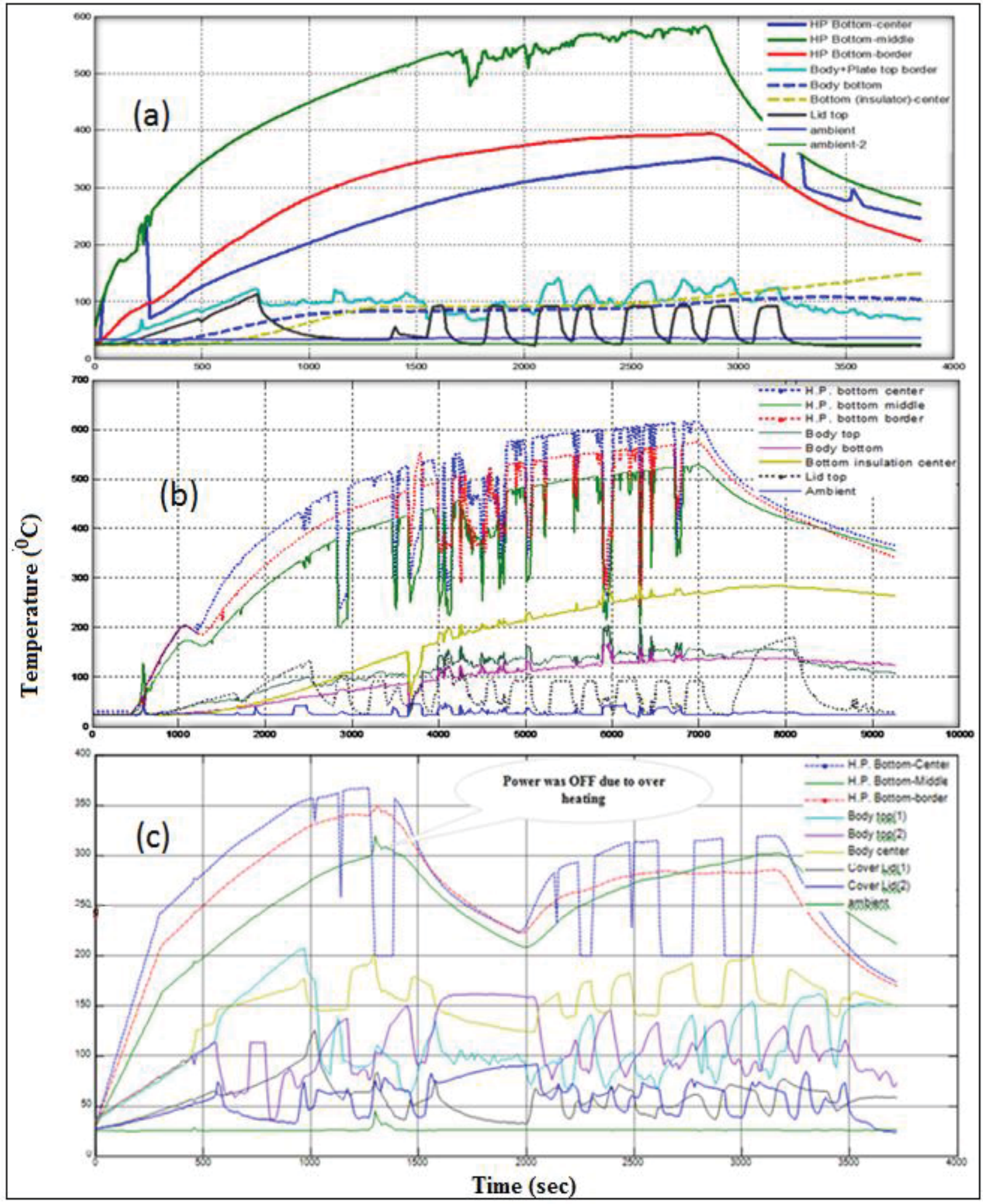

Figure 11. Temperature profile of the three type of electrical mitad, (a) Temperature profile of the single clay mitad, (b) Temperature profile of double clay type mitad and (c) Temperature profile of the rotating type mitad (N.B: subscript 1 represents the clay that contains the heating element, 2 represents the dependent clay). 
The non-uniformity of the heating likely occurs as a result of the inaccuracy of the manufacturing process of the mitad itself. Such manufacturing error includes the difference in the depth of the groove the electrical resistor is embedded and the difference in density of the resistor rolling across its length. Furthermore, it indicates that even though the baking surface has reached the required baking temperature at early period of the heating up process (i.e. after $1200 \mathrm{sec}$ from starting); the temperature of the heating element is increasing which means the system is consuming additional power from the source irrelevantly (though some power will be consumed for increasing the temperature of the batter during the baking process). As a result, that additionally consumed energy is being dissipated in the form of different losses such as side loss, bottom loss and top losses.

Figure $11 \mathrm{~b}$ and $\mathrm{c}$ indicate that the temperature profile of the different sections of the double clay and rotating type mitad respectively. The general approach in these mitad is also similar to that of the singly clay mitad. As compared to the single clay mitad, it can be observed that the double clay mitad reaches the baking temperature relatively slower (i.e. 24 minutes) while it also consumes higher energy. Furthermore, heating non-uniformity and temperature increment during baking process shows similar behavior with that of the single layer mitad, but with slower rateIn the rotating type mitad, the non-uniformity of heating in a given clay (i.e. either the dependent clay or the heating clay) is not significant as compared to the other two types of mitad discussed above. The baking surface attains the required baking temperature $\left(130^{\circ} \mathrm{C}\right)$ faster as compared to the other two mitad, with the time requirement of 15 minutes. In this type of mitad, the problem of different heating patterns of the two baking clays was identified, the first clay (heating element holder) heats-up faster than the second (dependent clay), which created an overheating problem to the first clay and forces to turn OFF the power source for a while during the testing period. Even though this problems can be resolved by using proper thickness (i.e. proportionally varied thickness) of the two clays so that it will deliver uniform heating on the baking surface, but it is not widely addressed by the mitad manufacturers.

As the baking process is started (i.e. opening of the coverlid and staring of baking), the motion has resulted measurement irregularities in thermocouples, as indicated in figure 11, seen after the power is turned off or starting of baking in each curve for the three type of mitad.

\subsection{Energy Consumption Performance}

The energy consumption of the different mitad is measured by undertaking a baking process of 8 to 13 pcs injera. The measurement data from the performance testing is indicated in table 4 . It can 
Table 4. Summary of measurement data from baking performance test.

\begin{tabular}{|llll|}
\hline \multirow{2}{*}{ Description } & \multicolumn{3}{c|}{ Mitad Type } \\
\cline { 2 - 4 } & Double clay & Single clay & Rotating type \\
\hline Input Voltage (V) & 210.00 & 207 & 207 \\
\hline Input Current (A) & 17.00 & 17 & 17.5 \\
\hline Mitad power requirement (kW) & 3.57 & 3.52 & 3.62 \\
\hline Energy Consumption & & & \\
\hline $\begin{array}{l}\text { Energy for heat-up (kWh) } \\
\text { • Net energy consumption for baking } \\
\quad \text { only (kWh) }\end{array}$ & 1.49 & 1.42 & 1.10 \\
\hline$\bullet \quad 3.01$ & 1.50 & 1.90 \\
\hline Total Injera baked (number) & 4.50 & 2.92 & 3.00 \\
\hline Total Injera baked (kg) & 12.00 & 8 & 13 \\
\hline Total mass of water evaporated (kg) & 5.25 & 3.06 & 5.35 \\
\hline $\begin{array}{l}\text { Time for Heat-up (min) } \\
\text { Time for only baking process (min) }\end{array}$ & 1.82 & 1.26 & 2.10 \\
\hline
\end{tabular}

Table 5. Summary of analysis on the energy consumption of the three type of mitad.

\begin{tabular}{|c|c|c|c|}
\hline \multirow[t]{2}{*}{ Description } & \multicolumn{3}{|c|}{ Mitad Type } \\
\hline & Double & Single & Rotating \\
\hline Mitad power requirement $(\mathrm{kW})$ & 3.57 & 3.52 & 3.62 \\
\hline \multicolumn{4}{|l|}{ Gross Energy Consumption (Input Energy) } \\
\hline - Energy for heat up [KJ] & 5364 & 5112 & 3960 \\
\hline - Energy for baking only, without heating up [KJ] & 10836 & 5400 & 6840 \\
\hline - Gross energy consumption for the baking process [KJ] & 16200 & 10512 & 10800 \\
\hline \multicolumn{4}{|l|}{ Specific Energy Consumption (Input Energy) } \\
\hline - Energy for baking only, without heating up (kWh/pcs) & 0.251 & 0.188 & 0.146 \\
\hline - Energy for baking only, without heating up (kWh/kg) & 0.573 & 0.490 & 0.355 \\
\hline - Energy for baking only, without heating up (kJ/pcs) & 903.00 & 675.00 & 526.15 \\
\hline - Energy for baking only, without heating up $(\mathrm{kJ} / \mathrm{kg})$ & 2064.00 & 1764.71 & 1278.50 \\
\hline \multicolumn{4}{|l|}{ Useful energy of the Injera process (Output Energy) } \\
\hline - $\quad$ Latent heat of water $(\mathrm{kJ})$ & 4111,59 & 2846,453 & 4734,698 \\
\hline - Sensible heat present in Injera $(\mathrm{kJ})$ & 1568,24 & 915,0133 & 1598,675 \\
\hline - $\quad$ Total useful energy for the baking process $[\mathrm{KJ}]$ & 5679,84 & 3761,467 & 6333,362 \\
\hline - Specific useful energy $[\mathrm{KJ} / \mathrm{Pc}]$ & 473,32 & 470,1833 & 487,1817 \\
\hline - Specific useful energy $[\mathrm{KJ} / \mathrm{Kg}]$ & 1081,874 & 1229,237 & 1183,806 \\
\hline Energy loss (not corrected) & 10520.2 & 6750.5 & 4466.6 \\
\hline Thermal efficiency of the baking process (not corrected) & $35.1 \%$ & $35.8 \%$ & $58.6 \%$ \\
\hline
\end{tabular}


be seen that while all mitad has relatively the same power rating (i.e. $3.5 \mathrm{KW}$ ), the rotating type mitad consumes the least energy for heating up $(1.10 \mathrm{KWh})$ as well as for the baking process $(1.90 \mathrm{KWh})$ for $13 \mathrm{pcs}$ of injera as compared to the other type of mitad. The time for heat up and baking is much shorter for the rotating type than the other type of mitad.

The summary of the analysis on the energy consumption of the three type of mitad is indicated in table 5. The heat loss on the double clay type is 2.35 times higher than the rotating type and about 1.5 times higher than single clay type. The single clay type has better performance than double type, however, the heat loss with respect to rotating type is about 1.5 times higher. The heat loss from rotating type is less than the other types, this implies it has a good benefit in view of energy conservation but it has technical complexity during operation.

The total useful energy, that is the sum of total Sensible heat gain and Latent heat gains, will only depend on the number of Injera baked, not on the type of mitad used. The average specific useful energy consumption is an important parameter for designing of any injera baking system and this value is determined to $480 \mathrm{KJ} / \mathrm{pc}$ injera (with a variation of $\pm 2 \%$ ) or $1180 \mathrm{KJ} / \mathrm{Kg}$ injera (with a variation of $\pm 5 \%$ ).

Since, the number of Injera or total masses of Injera baked at each types of the mitad are different, the energy consumption comparison shall be normalized for the same number or amount of injera baked. Thus for purpose of normalized comparisons, the initial energy consumption data is normalized for a consumption of $12 \mathrm{pcs}$ or $6 \mathrm{~kg}$ of injera, as presented in table 6 . The specific average baking energy is $0.73 \mathrm{kWh} / \mathrm{kg}, 0.82 \mathrm{kWh} / \mathrm{kg}$ and $0.54 \mathrm{kWh} / \mathrm{kg}$ for single clay, double clay and rotating type mitad respectively.

The thermal efficiency as presented under equation 5 , it is the ratio of the useful energy required to the actual energy consumed. As presented in table 7, the corrected thermal efficiency is $38 \%$, $47 \%$, and $62 \%$ for double clay, single clay and rotating type electrical mitad respectively. It can also be noted that the useful specific energy consumption $(480 \mathrm{KJ} / \mathrm{pc}$ or $1180 \mathrm{KJ} / \mathrm{Kg})$ is relatively the same for all type of mitad.

The rotating type mitad has the minimal specific energy consumption $(\mathrm{kWh} / \mathrm{kg}$ injera or $\mathrm{KWh} / \mathrm{pc}$ injera) over both type of mitad while the singly clay mitad has better performance over the double clay mitad. However, it had different technical challenges during manufacturing stage and operation. During operations there was a problem of rolling of the unfinished baked Injera over the top cover (aluminum lid), flow of the batter to the ground during rotation and as a result it was 
difficult to get aesthetically attractive injera. There was also a problem of unequal heating of both clays hence it created additional challenge to operate both clays steadily.

Table 6. Summary of normalized energy consumption comparison and time analysis.

\begin{tabular}{|c|c|c|c|}
\hline \multirow[t]{2}{*}{ Description } & \multicolumn{3}{|c|}{ Mitad Type } \\
\hline & Double & Single & Rotating \\
\hline \multicolumn{4}{|l|}{ Normalized Energy consumption and time requirement } \\
\hline - Energy requirement for heat up ( $\mathrm{kWh})$ & 1.49 & 1.42 & 1.10 \\
\hline $\begin{array}{l}\text { - Specific energy consumption for baking only } \\
(\mathrm{KWh} / \mathrm{Kg})\end{array}$ & 0.573 & 0.490 & 0.355 \\
\hline $\begin{array}{l}\text { - Specific energy consumption for baking only } \\
(\mathrm{KWh} / \mathrm{Pc})\end{array}$ & 0.251 & 0.188 & 0.146 \\
\hline - Useful energy output (kJ/Pc Injera) & 473.32 & 470.18 & 487.18 \\
\hline - Useful energy output $(\mathrm{kJ} / \mathrm{Kg}$ Injera) & 1107.18 & 1229.24 & 1183.80 \\
\hline - $\quad$ Time for heat up process [min] & 24.0 & 20.0 & 15.0 \\
\hline $\begin{array}{l}\text { - Time for baking process only, without heat up } \\
{[\mathrm{min} / \mathrm{pc}]}\end{array}$ & 4.67 & 4.25 & 3.62 \\
\hline $\begin{array}{l}\text { - Time for baking process only, without heat up } \\
{[\mathrm{min} / \mathrm{Kg}]}\end{array}$ & 10.67 & 11.11 & 8.79 \\
\hline \multicolumn{4}{|l|}{ Comparison based on 12 pcs of injera baking } \\
\hline - Energy consumption for baking only [KWh] & 3,01 & 2,25 & 1,75 \\
\hline $\begin{array}{l}\text { - Total energy consumption for } 12 \mathrm{pcs} \text { injera } \\
\text { [KWh] }\end{array}$ & 4,50 & 3,67 & 2,85 \\
\hline - Specific energy consumption $(\mathrm{KWh} / \mathrm{Pc})$ & 0.375 & 0.306 & 0.238 \\
\hline - Total energy consumption for $12 p c s$ injera $[\mathrm{KJ}]$ & 16200,00 & 13212,00 & 10273,85 \\
\hline - Useful energy output for $12 \mathrm{pcs}$ injera [KJ] & 5679,84 & 5642,20 & 5846,18 \\
\hline - Thermal Efficiency [\%] & 35.1 & 42.7 & 56.9 \\
\hline \multicolumn{4}{|l|}{ Comparison based on $6 \mathrm{Kg}$ of injera baking } \\
\hline - Energy requirement for heat up [kWh] & 1,49 & 1,42 & 1,10 \\
\hline - Energy consumption for baking only [KWh] & 3,44 & 2,94 & 2,13 \\
\hline - Total energy consumption for $6 \mathrm{Kg}$ injera [KWh] & 4,93 & 4,36 & 3,23 \\
\hline $\begin{array}{l}\text { - Specific energy consumption, of the total } \\
(\mathrm{KWh} / \mathrm{Kg})\end{array}$ & 0.822 & 0.727 & 0.538 \\
\hline - Total energy consumption for $6 \mathrm{Kg}$ injera $[\mathrm{KJ}]$ & 17748,00 & 15700,24 & 11631,03 \\
\hline - Useful energy output for $6 \mathrm{Kg}$ injera [KJ] & 6643,09 & 7375,42 & 7102,81 \\
\hline - Thermal Efficiency [\%] & 37.4 & 47.0 & 61.1 \\
\hline \multicolumn{4}{|l|}{ Comparison based on time of baking process } \\
\hline - Corrected total time required ( $\mathrm{min} / \mathrm{pc}$ injera) & 6.67 & 5.92 & 4.87 \\
\hline - Corrected time required ( $\mathrm{min} / \mathrm{Kg}$ injera) & 14.67 & 14.44 & 11.29 \\
\hline
\end{tabular}


The energy consumption analysis presented in table 5 is an average energy consumption characteristic of a typical mitad, with an average mitad capacity of $3.57,3.52$ and $3.62 \mathrm{KW}$ for double clay, single clay and the rotating type mitad respectively. As different mitad have slightly varying capacity, the performance analysis characteristics will show slight variation but the general trend for all performance parameters remain the same. A similar extensive analysis on a double clay, single clay and rotating type mitad with slightly different capacity of $3.71,3.74$ and 3.62KW respectively have a thermal efficiency of $38.3,49.5$ and $64.2 \%$ respectively.

The energy consumption performance indicators of a given mitad will also depend on the life cycle utilization of the mitad i.e. older mitad will have lower performance than new mitad. Even though life-cycle energy-consumption performance analysis gives more accurate indicator, it is expected that the mitad performance will deteriorate as the respective mitad gets older. Therefore, the performance indicator such as the baking efficiency from the above analysis are expected to be the maximum limitations. Therefore, the above analysis and its resulting performance indicators are justifiable from cost perspective. Similarly as the number (pcs) or amount $(\mathrm{Kg})$ of injera-baked increases, the thermal efficiency of a given mitad will also increase as the heating up energy consumption is the same. In general, it can be noted that the energy consumption performance of existing mitad design is low, with average efficiency of 40, 50 and $65 \%$ for double clay, single clay and rotating type mitad respectively.

\subsection{Energy Loss Analysis}

The energy losses that are extracted from the gross and the useful energy consumption analysis discussed in the above sections for each of the existing design types is revised and presented in table 7 . Though the rotating type mitad has better energy consumption performance because of its technical problems, those commonly used electrical mitad in every household are either the single or the double clay mitad. Considering the difference in performance of the existing two commonly applied mitad, the single clay mitad has an energy saving of $0.095 \mathrm{KWh} / \mathrm{kg}$ of injera over that of the double clay mitad. If an average person daily injera consumption is assumed to be $1 \mathrm{~kg}$, then this would mean an energy saving of $35 \mathrm{KWh} /$ per year per person. This difference is even higher, if the grid transmission and distribution loss is considered. For an average household with family size of 5 to 6 members, this energy loss from the double clay mitad would mean 1 to 2 month additional electricity bill as compared to a household using the single clay mitad. Therefore, the energy saving that can be obtained by just choosing the existing single clay mitad over that of the 
double clay mitad would have significant impact at every household in particular and the national grid in general.

However, such awareness for energy saving is very low. The research has found out mitad manufacturers usually advise clients to purchase the double clay mitad than the single clay mitad claiming its simplicity (i.e. if the baking clay is damaged, then it can easily be replaced by other clay without affecting the clay holding the electrical resistor) hence lower maintenance cost. For the case of single clay mitad, if there is maintenance then it means there is a requirement to create coil-holding grooves in the newly replaced clay, implying higher maintenance cost. The research has found out that electrical mitad usually function for about 3 to 5 years without the requirement of maintenance. Therefore, the wide perception of minimal maintenance cost over that of energy saving in mitad manufacturers and users is wrongly perceived and widely practiced.

Table 7. Summery for the energy loss analysis of the existing mitad.

\begin{tabular}{|c|c|c|c|}
\hline \multirow[t]{2}{*}{ Description } & \multicolumn{3}{|c|}{ Mitad type } \\
\hline & Double & Single & Rotating \\
\hline \multicolumn{4}{|l|}{ Comparisons based on 12 unit Injera } \\
\hline - Useful Energy consumption for 12 Injera $(\mathrm{kJ})$ & $5,679.84$ & 5642.20 & $5,846.18$ \\
\hline - Gross energy consumed for 12 Injera $(\mathrm{kJ})$ & $16,200.00$ & $13,212.00$ & $10,273.85$ \\
\hline - Total Energy Loss for 12 Injera (KJ) & $10,520.16$ & $7,569.80$ & $4,427.67$ \\
\hline - Overall thermal efficiency (corrected) & $35.1 \%$ & $42.7 \%$ & $56.9 \%$ \\
\hline - Corrected total time required ( $\mathrm{min} / \mathrm{pc}$ injera) & 6.67 & 5.92 & 4.87 \\
\hline - Minimum useful power rating of the mitad [KW] & 1.18 & 1.32 & 1.67 \\
\hline - Power loss [KW] & 2.39 & 2.20 & 1.95 \\
\hline \multicolumn{4}{|l|}{ - Comparisons based on $6 \mathrm{Kg}$ of injera } \\
\hline - Useful energy for $6 \mathrm{~kg}$ of Injera $(\mathrm{kJ})$ & 6643,09 & 7375,42 & 7102,81 \\
\hline - Gross energy consumed for $6 \mathrm{~kg}$ of Injera $(\mathrm{kJ})$ & 17748,00 & 15700,24 & 11631,03 \\
\hline - Total Energy Loss for $6 \mathrm{~kg}$ of Injera (kJ) & 11104,91 & 8324,81 & 4528,22 \\
\hline - Overall thermal efficiency (corrected) [\%] & $37.4 \%$ & $47.0 \%$ & $61.1 \%$ \\
\hline - Corrected total time required ( $\mathrm{min} / \mathrm{pc}$ injera) & 14,67 & 14,44 & 11,29 \\
\hline - Minimum useful power rating of the mitad [KW] & 1,26 & 1,42 & 1,75 \\
\hline - Power loss [KW] & 2,31 & 2,10 & 1,87 \\
\hline
\end{tabular}

The important parameters that would affect the improvement works of any Injera baking mitad are the estimated useful energy demand and required time per each baking sessions. As indicated in table 7 , to bake one Injera within $6.67 \mathrm{~min}$ or $1 \mathrm{~kg}$ of Injera within $14.67 \mathrm{~min}$ by using double clay type mitad needs at least $1.26 \mathrm{~kW}$ of power input. If someone is interested to reduce the power 
input, the other parameters are unchanged; it implies that there would be sacrifice to wait some longer times per each Injera baked. Similarly, for single clay and rotating type mitad needs $1.42 \mathrm{~kW}$ and $1.75 \mathrm{~kW}$ of useful power to bake an Injera within $5.92 \mathrm{~min}$ and $4.87 \mathrm{~min}$ or $1 \mathrm{~kg}$ of Injera within $14.44 \mathrm{~min}$ and $11.29 \mathrm{~min}$ respectively.

The minimum useful power demand is, therefore, $1.26 \mathrm{~kW}, 1.42 \mathrm{~kW}$ and $1.75 \mathrm{~kW}$ respectively for double clay, single clay and rotating type mitad to bake with the time intervals as specified in table 7. This imply that the best-designed electrical mitad should have a power rating of $1.26 \mathrm{~kW}$, $1.42 \mathrm{~kW}$ and $1.75 \mathrm{~kW}$ respectively. As the existing mitad have higher input power, the loss of power from each type would be $2.39,2.20$, and 1.95 respectively for double clay, single clay and rotating type mitad respectively. Therefore for a higher thermal efficiency requirement (for example $80 \%$ ), the electrical mitad design shall have a power rating in the range of 1.6-1.9 KW. As presented with the temperature profile of the different components of the mitad in figure 11, most of this heat is also lost through the bottom insulation. Therefore, the utilization of effective insulation material is expected to reduce energy loss of the system and hence enabling to design lower power rating of the electrical mitad (i.e. 1.6 to $-1.9 \mathrm{KW}$ capacity).

\section{CONCLUSION AND RECOMMENDATION}

From the assessment study of the existing mitad designs in Mekelle city, the electrical mitad which has a power consumption of $3.5 \mathrm{~kW}$ to $3.9 \mathrm{~kW}$ is the most energy-consuming device in every household. The specific average baking energy is $0.82 \mathrm{kWh} / \mathrm{kg}, 0.73 \mathrm{kWh} / \mathrm{kg}$, and $0.54 \mathrm{kWh} / \mathrm{kg}$ for double clay, single clay and rotating type mitad respectively. The thermal efficiency comparisons by considering baking of $6 \mathrm{~kg}$ of Injera on each of mitad is $38 \%, 47 \%$, and $62 \%$ respectively for double clay, single clay and rotating type of existing designs.

Because of its technical limitation, the energy efficient rotating type mitad does not have wider use thus, those widely electrical mitad in every household are either the single or the double clay mitad. These widely used electrical mitad have energy loss from $50-60 \%$ of the input energy. This loss is significant. Even without design improvement options, the existing single clay mitad would have an energy saving of at least $35 \mathrm{KWh} /$ per year per person over that of the double clay mitad. Therefore, the energy saving that can be obtained by just choosing the existing single clay mitad over that of the double clay mitad would have significant impact at every household in particular and the national grid in general. However the awareness for energy saving is very low at all level, 
from the mitad manufacturers to end user. This needs be addressed with implementation of appropriate policies and standardization of more efficient mitad at local manufacturing workshops. The significant losses in the current electric mitad can also be minimized by applying different design improvements. The possible options for the improvement of the electric mitad would be attained from the reduction of the thickness of the baking clay, thermal conductivity improvement works of the baking clay, the insulation thickness increment, selecting a better and cheap thermal insulation material and proper dimensioning of the electrical resistor. An improvement in one or a combination of the above options would significantly reduce the losses and improve the efficiency of the mitad. Other improved innovative system, such as metal plate based baking system, solar stove etc. may also improve the overall performance of the injera baking process.

\section{ACKNOWLEDGEMENTS}

The Authors would like to thank the EnPe project (EnPe 2009-2014) of School of Mechanical and Industrial Engineering and the Research and publication office (RPO) of EiT-M for providing the cost of this study.

\section{REFERENCE}

Adrian, Bejan \& Allan, D. Kraus. 2003. Heat Transfer Handbook. John Wiley and Sons, ISBN 0471-39015-1, 1496p.

Alula Gebresas \& Asmamaw Tegegne. 2011. Improving energy consumption and durability of the clay bakeware (Mitad). M.Sc. thesis, Department of Material Science and Engineering, College of Natural and Computational Science, Hawassa Univeresity, Hawassa, Ethiopia. (Unpubl.)

Awet, Haftu. 2011. Enhancing the Thermal Conductivity of the Mitad Clay. M.Sc. Thesis, School of Mechanical and Industrial Engineering, Institute of Technology, Bahir Dar University, Bahir Dar, Ethiopia. (Unpubl.)

Dave Sood. 2010, Injera Electric baking: Energy use impacts in Addis Ababa Ethiopia, Report submitted to Ethiopian Electric Power Company and The World Bank Africa Region, Ethiopian Energy Authority, http://www.ethioenergyauthority.gov.et accessed on March 2016. 
Frank, K., Raj, M. M \& Mark, S. B. 2011. Principles of heat transfer. $7^{\text {th }}$ Edition, Cengage Learning, INC., Stanford, USA, ISBN-13: 978-0495667704, ISBN-10: 0495667706, pp $377-417 \& 707-826$.

Gebreegziabher Zenebe. 2004. Urban Domestic Energy Problems in Ethiopia: An Overview. Ethiopian Development Research Institute, Addis Ababa, Ethiopia. Report published at Environment for Development (EfD) Initiative, http://www.efdinitiative.org/publications, accessed on March 2016.

Gebreegziabher Zenebe, 2007. Household Fuel Consumption and Resource Use in Rural-Urban Ethiopia. PhD Thesis, Department of Social Sciences, Wageningen University. Report published at Environment for Development (EfD) Initiative, http://www.efdinitiative.org/ publications, accessed on March 2016.

GIZ, 2011. The Energy Development Intervention in Ethiopia. Report, GiZ Energy Coordination Office, Ethiopia (GiZ ECO Ethiopia), report available at World Bank, www.worldbank.org accessed on March 2016.

Incropera, Frank P., David P. DeWitt, Theodore L. Bergman \& Adrienne S. Lavine, 2007. Fundamentals of heat and mass transfer. John Wiley \& Sons, Inc. ISBN;0-471-76115-X.

John, H. Lienhard V \& John, H. Lienhard IV. 2008. A Heat Transfer. $3^{\text {rd }}$ Edition, Phlogiston Press, ISBN-13: 978-0971383531, 760p.

RTPC (Rural Technology Promotion Center). 1998. Biomass Stove (Mogogo Eton). Test Report, RTPC, Mekelle, Ethiopia.

Yunus, A. Cengel. 2002. Heat Transfer- A Practical Approach. $2^{\text {nd }}$ Edition, Mac Graw Hill, ISBN13:978-0072458930; ISBN-10: 0072458933, 932p. 


\section{NOMENCLATURE}

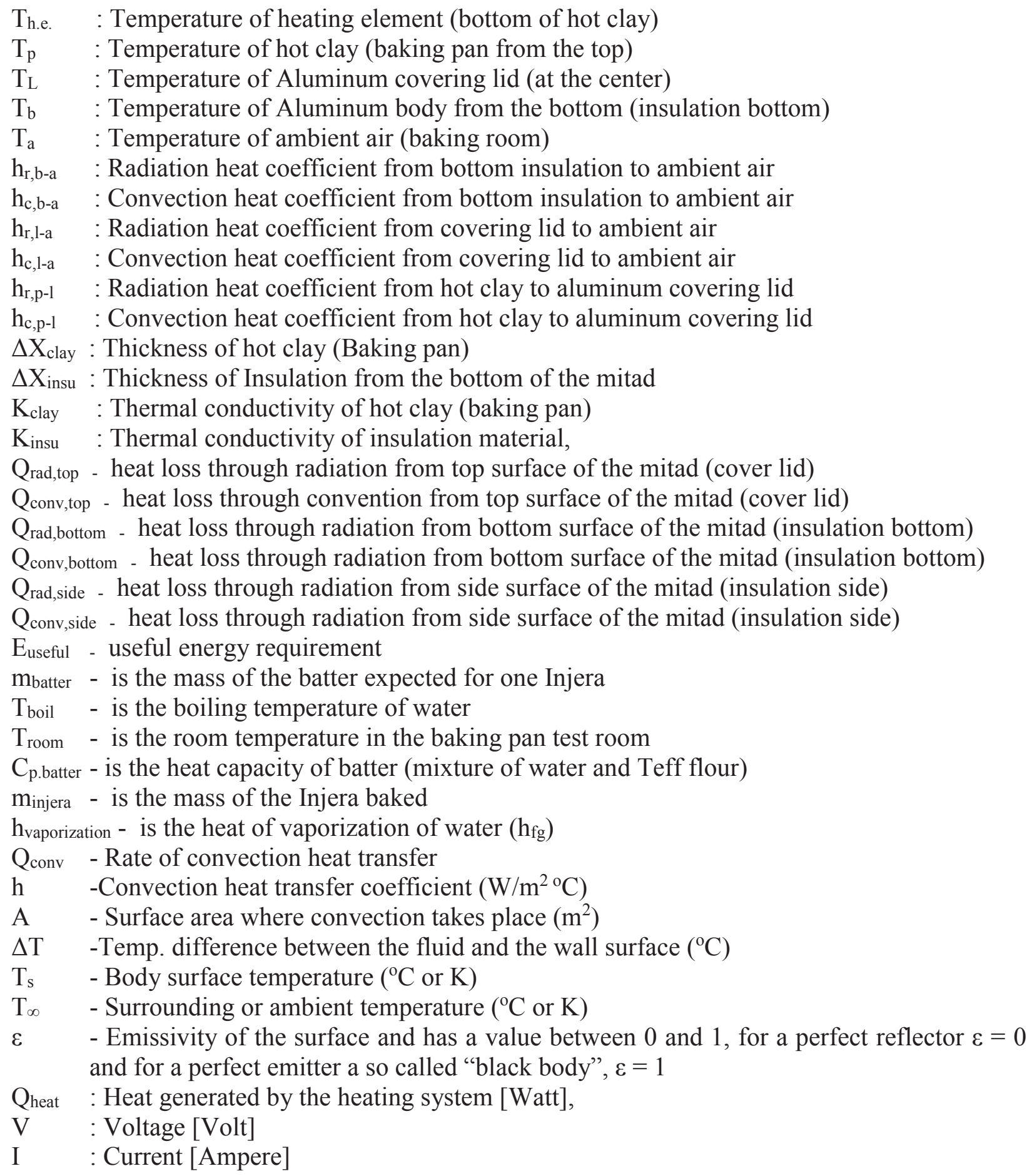

